\title{
Fluctuating asymmetries and reproductive success in the peacock blenny
}

\author{
D. M. Gonçalves*, P. C. Simões, A. C. Chumbinho, M. J. Correia, \\ T. FAGUndes AND R. F. Oliveira \\ Unidade de Investigação em Eco-Etologia, Instituto Superior de Psicologia Aplicada, \\ Rua Jardim do Tabaco 34, 1149-041 Lisboa, Portugal
}

(Received 25 July 2001, Accepted 19 January 2002)

\begin{abstract}
In an investigation of the relationship between reproductive success and fluctuating asymmetry (FA) in the peacock blenny Salaria pavo, FA was measured in four bilaterally paired characters in successful and unsuccessful males during the breeding season. Reproductive success among successful males was assessed by calculating the number of eggs the males were defending. Absolute FA values relative to trait size were high for all characters and it is suggested that this could be a consequence of sub-optimal environmental conditions. Two of the traits presented higher absolute FA values suggesting a lower canalization during ontogeny. No difference in FA between successful and unsuccessful males was found and no relationship between FA and number of eggs among the successful males occurred for any of the measured traits. A composite index of FA, that should better reflect overall developmental competence, was also unrelated to reproductive success. These results indicate that FA is not associated with reproductive success among males of $S$. pavo. Successful males were larger than unsuccessful males and a strong positive correlation was detected between the body length of the parental males and the number of eggs they had in the nest, even when controlling for the internal nest area. Body size may give males a reproductive advantage by being preferred by females and by having an advantage in male-male competition for nests of higher quality.
\end{abstract}

(C) 2002 The Fisheries Society of the British Isles. Published by Elsevier Science Ltd. All rights reserved.

Key words: fluctuating asymmetry; developmental stability; Salaria pavo; peacock blenny; reproductive success.

\section{INTRODUCTION}

It has been suggested that departures from perfect symmetry are inversely correlated with fitness (van Valen, 1962; Thornhill, 1991; Møller, 1994). Individuals with lower developmental competence should use proportionally more resources to maintain a stable phenotype and, consequently, a lower reproductive success of asymmetric individuals would be predicted (Møller \& Swaddle, 1997). Published studies relating flyctuating asymmetry (FA) with reproductive success, however, have produced controversial results. For example Møller (1992) found the predicted negative correlation between tail length asymmetry and fecundity in the barn swallow and Downhower et al. (1990) describes a negative relationship between otolith asymmetry and reproductive success in Cottus bairdi Girard. Dufour \& Weatherhead (1998), however, found no relation between asymmetry of five bilaterally paired characters and reproductive success in male red-winged black birds and Sasal \& Pampoulie

*Author to whom correspondence should be addressed. Tel.: +351 21881 1700; fax: +35121 886 0954; email: davidg@ispa.pt. 
(2000) found no relationship between pectoral fin asymmetry and the number of eggs in the nest of Pomatoschistus microps (Krøyer).

In the present study, the relationship between FA levels and reproductive success in males of the peacock blenny Salaria pavo (Risso) was evaluated. This species occurs in the intertidal of Mediterranean and adjacent Atlantic rocky coasts (Zander, 1986). It exhibits a strong sexual dimorphism with males being larger than females and having a pronounced head crest, and the first two rays of the anal fin transformed into an anal gland which may produce a pheromone that attracts females (Fishelson, 1963; Laumen et al., 1974; Papaconstantinou, 1979; Patzner et al., 1986; Patzner \& Seiwald, 1987; Zeeck \& Ide, 1996). Both sexes present supra-orbital dark eyespots surrounded by an iridescent blue ring and the body flanks present numerous blue dots and stripes. Males defend nests and guard eggs layed by several females throughout the breeding season and the same female may spawn with several males during the same breeding season (Patzner et al., 1986). The eggs are attached to the nest walls in a single layer of roughly uniform density (Fishelson, 1963; Patzner, 1984; Oliveira et al., 1999). A population of $S$. pavo occurring in a mudflat area at Ria Formosa (southern Portugal) which is close to the species western limit of distribution (Canary Islands, Dooley et al., 1985; Zander, 1986) was investigated in the present study. The only available hard substratum appropriate for $S$. pavo nests in this area are bricks that are used by clam culturists to delimit their fields. The strong competition for the access to these nests by males causes a reduction in territory size, with males avoiding leaving the nest and not defending any territory around it (Almada et al., 1994). At the peak of the breeding season most nests are almost completely covered with eggs, becoming a limiting factor for female spawning (Almada et al., 1994). This leads in this population to a reversal of the sex roles in courtship with females being the courting sex (Almada et al., 1995). Female choice for males, however, is also likely to take place. Several males may nest in the same brick and often their reproductive success varies (pers. obs.), suggesting that females prefer to spawn with particular males or in particular nests.

It should be clear, however, that female choice for symmetry (Schlüter et al., 1998 ) is not the only possible mechanism giving symmetric males a reproductive advantage. For example, symmetric males may grow more, as demonstrated in other species (e.g. muskrats, Pankakoski, 1985), and gain advantage in malemale competition for the access to higher quality nests or may have a higher longevity (e.g. barn swallows, Møller, 1994) and thus reproduce for a longer period (Møller \& Swaddle, 1997).

In the present study the prediction that FA levels are negatively correlated with reproductive success in $S$. pavo males was tested. The FA of four traits was compared between successful and unsuccessful males and the relationship between FA and reproductive success among successful males investigated.

\section{MATERIAL AND METHODS}

A population of $S$. pavo at the Ria Formosa Nature Park (Algarve, Portugal; 36 $59^{\prime} \mathrm{N}$; $7^{\circ} 51^{\prime} \mathrm{W}$ ) was studied. A total of 39 males was collected from 12 to 16 June 2000, at the peak of the species breeding season (Almada et al., 1994). Males were collected from 
bricks delimiting a clam field during low tide with a hand net and anaesthetized with MS222 (Sigma, Lisbon, Portugal). The fish standard length $\left(L_{\mathrm{s}}\right)$, maximum dorsal fin height and crest height was measured with a ruler to the nearest $0 \cdot 1 \mathrm{~cm}$. The development of the anal gland and of the genital papilla was classified on an ordinal scale from 0 (not developed) to 3 (well developed). The number of eggs males were defending was then estimated and FA for four variables was measured, as described below.

\section{REPRODUCTIVE SUCCESS ESTIMATES}

The only available method to estimate the reproductive success of males in natural nests of $S$. pavo without destroying them is to calculate, by visual inspection, the percentage of the nest area covered with eggs, in relation to the total nest inner area (Oliveira et al., 1999). This estimate, however, can be a crude measurement of reproductive success as the error associated with estimation of the egg mass area can be large and egg density can vary from nest to nest.

The suitability of this indirect method was compared with a more direct method. Eleven breeding males, were collected and removed from their nests, which consisted of holes in bricks. The nest inner area was measured with a ruler to the nearest $0 \cdot 1 \mathrm{~cm}$ and the percentage of the nest area covered with eggs calculated by visual inspection. The brick was cut-open and the nest area occupied by the egg mass was drawn on a transparent plastic sheet. To evaluate the egg density in each nest a Sony Hi8 handycam was used to take six still frames in six different areas of the egg mass with a $1 \mathrm{~cm}^{2}$ frame placed over the eggs. The images were later imported to a computer and the number of eggs per $\mathrm{cm}^{2}$ counted using the freeware software UTHSCSA Imagetool ${ }^{\odot} \mathrm{V} 2.00$. The drawings of the eggs masses were also imported to a computer and calculations of the total area occupied by the eggs in each nest performed using the same software. In the first method the total number of eggs in each nest was calculated by multiplying the estimated area occupied with eggs by the average egg density value obtained for all nests $\left(80\right.$ eggs $\left.\mathrm{cm}^{2}\right)$. In the second method the total area occupied by the egg mass was multiplied by the average egg density value for that nest. The eleven males were taken to the laboratory for further experiments and will eventually be released at the same place where they were captured.

The number of eggs calculated by both methods was correlated (Spearman rank correlation: $r_{s}=0 \cdot 74, n=11, P<0 \cdot 01$ ) and did not differ significantly (Wilcoxon matched pairs test: $Z=1 \cdot 60, n=11, P=0 \cdot 11)$. Thus, estimating the number of eggs based on visual inspection of the nests seems to be an accurate measure of reproductive success. This method was then applied to calculate the number of eggs the 39 males, used in FA estimates, were defending without destroying their nests.

\section{FLUCTUATING ASYMMETRY}

Variables used to calculate FA in $S$. pavo were the length of the pectoral and pelvic fins $(n=39)$, the area of the eyespots $(n=38)$ and the number of blue marks (dots plus stripes) on the fish flanks $(n=38)$. Each of these variables was measured six times to distinguish asymmetry from measurement error (Swaddle et al., 1994). Length of the pectoral and pelvic fins were measured in the field by the same observer with a calliper to the nearest $0.1 \mathrm{~mm}$, alternating one left side measurement with one right side measurement. A second observer acted as recorder. No wounds were observed on the fins. The area of the eyespots and the number of blue marks on the fish flanks were measured from video images taken in the field. Although fish get darker when anaesthetized, the number of blue marks and the area of the eyespot do not change with anaesthesia. All fish were filmed with a Sony Hi8 handycam at an angle of $90^{\circ}$, at the same focal distance, with a ruler placed below the fish to be later used as a scale. One side of the fish was filmed, the fish was turned over and the other side also filmed. This procedure was repeated six times, after which the fish was allowed to recover from the anaesthesia in a container with abundant water. No fish died during measurements and all animals were returned to their original nests. All males had been marked at the beginning of the breeding season with PIT tags (TROVAN ${ }^{\circledR}$, Madrid, Spain) for another study. These magnetic marks allowed identification of individuals preventing measuring the same male on consecutive 
TABLE I. Statistical properties of the measured traits and of the absolute FA [(R $-\mathrm{L})]$. Mean and range values for the measured traits were calculated from six replicated measurements for each side

\begin{tabular}{|c|c|c|c|c|c|}
\hline \multirow[b]{2}{*}{ Variables } & \multirow[b]{2}{*}{$n$} & \multirow[b]{2}{*}{ Mean \pm S.E. } & \multirow[b]{2}{*}{ Range } & \multicolumn{2}{|c|}{ Absolute FA } \\
\hline & & & & Mean \pm S.E. & $\begin{array}{c}\text { Trait size } \\
\%\end{array}$ \\
\hline Pectoral fins length $(\mathrm{cm})$ & 39 & $17 \cdot 68 \pm 0 \cdot 21$ & $12 \cdot 37-20 \cdot 77$ & $0 \cdot 27 \pm 0 \cdot 04$ & $1 \cdot 53$ \\
\hline Pelvic fins length $(\mathrm{cm})$ & 39 & $11 \cdot 03 \pm 0 \cdot 12$ & $8 \cdot 27-13 \cdot 62$ & $0.29 \pm 0.08$ & $2 \cdot 63$ \\
\hline Eye spot area $\left(\mathrm{mm}^{2}\right)$ & 38 & $14 \cdot 74 \pm 0 \cdot 47$ & $8 \cdot 00-25 \cdot 72$ & $1 \cdot 96 \pm 0 \cdot 20$ & $13 \cdot 30$ \\
\hline Body marks frequency & 38 & $87 \cdot 72 \pm 1 \cdot 85$ & $50 \cdot 17-123 \cdot 50$ & $4 \cdot 96 \pm 0 \cdot 59$ & $5 \cdot 65$ \\
\hline
\end{tabular}

days. Still frames of the video images were later imported to a computer and calculations of the eyespot area $\left(\mathrm{mm}^{2}\right)$ and of the number of blue marks were performed for each of the six images recorded for the left and right flanks using the freeware software UTHSCSA Imagetool(C) V2.00. The filmed ruler was used to calibrate the scale for the eye spot area measurements.

\section{STATISTICS}

\section{Fluctuating asymmetry}

The procedures described by Palmer \& Strobeck (1986), Palmer (1994), Swaddle et al. (1994) and Møller \& Swaddle (1997) were followed to analyse FA data. A mixed model ANOVA was applied with factors: side (S: left or right), replicate (R: six replicates) and individual (I) as a random effect. An $F$-test given by the ratio between the mean square of $\mathrm{I} \times \mathrm{S}$ and of the combined mean squares of $\mathrm{I} \times \mathrm{S} \times \mathrm{R}$ and $\mathrm{I} \times \mathrm{R}$, could be estimated if variation due to FA was significantly greater than can be accounted for by the measurement error (Swaddle et al., 1994). The significance of counting error relative to asymmetry in the meristic trait (number of blue marks on the fish flank) was also analysed by this ANOVA technique because the differences between the sides were large (Table I) (Palmer, 1994).

As FAs are normally distributed around a mean of zero (Watson \& Thornhill, 1994) Shapiro-Wilks' W normality tests were applied, followed by one-sample $t$-tests to zero to distinguish relative FA $(\mathrm{R}-\mathrm{L})$ from antisymmetry and directional symmetry (Palmer, 1994).

To test if absolute FA $[(\mathrm{R}-\mathrm{L})]$ in the different measured traits correlated among individuals a mixed model, two-way ANOVA, with 'individuals' as a random effect and ' traits' as a fixed effect was applied. If some individuals exhibited, on average, higher asymmetry levels when data from the four traits were pooled, the effect of 'individuals' should be significant (Palmer, 1994).

The relationship between right-left differences and the size of the trait was investigated by linear regression analysis. As in many traits under stabilizing selection the relation between trait size and FA presents a ' U-shaped' distribution (Møller \& Swaddle, 1997) this relationship was also investigated by a second-order polynomial distribution.

Two indexes of FA were used to evaluate differences between sides. A relative measure of asymmetry $\left(I_{\mathrm{FAi}}\right)$ controlling for trait size was used to calculate asymmetry variation at each individual character, $I_{\mathrm{FAi}}=\left\{(\mathrm{R}-\mathrm{L})[0 \cdot 5(\mathrm{R}+\mathrm{L})]^{-1}\right\}^{2}$. To estimate the overall asymmetry of an individual a composite index $\left(I_{\mathrm{FAc}}\right)$ was computed which should be a more reliable indicator of overall developmental competence (Watson \& Thornhill, 1994; Leung et al., 2000). Males for which FA measurements were available for all characters $(n=38)$ were ranked for each of the measured variables from the most symmetrical (1) to 
TABLE II. Statistical properties of signed FA $(\mathrm{R}-\mathrm{L})$ for the four measured variables and results of normality tests and one-sample $t$-test to zero

\begin{tabular}{lrrrrrr}
\hline Variables & $n$ & $\begin{array}{c}\text { Mean } \\
( \pm \text { S.E. })\end{array}$ & Skewness & Kurtosis & $\begin{array}{c}\text { Shapiro-Wilks' } \\
(W)\end{array}$ & $t$-test \\
& & & & & \\
\hline Pectoral fins length & 39 & $-0.05 \pm 0.06$ & -0.42 & 1.78 & 0.95 & -0.85 \\
Pelvic fins length & 39 & $0.00 \pm 0.57$ & 1.79 & 12.67 & $0.72^{* * * *}$ & 0.04 \\
$\begin{array}{l}\text { Eye spot area } \\
\text { Body marks frequency }\end{array}$ & 38 & $0.58 \pm 0.37$ & -0.47 & -0.51 & 0.96 & 1.58 \\
& 38 & $0.33 \pm 1.01$ & -0.54 & 0.23 & 0.96 & 0.33 \\
\hline
\end{tabular}

${ }^{* * *} P \leq 0 \cdot 001$.

the least symmetrical (38), based on $I_{\mathrm{FAi}}$. The sum of these ranks was taken as a measure of overall asymmetry with the highest values of $I_{\mathrm{FAc}}$ indicating high levels of overall asymmetry.

\section{CORRELATES OF REPRODUCTIVE SUCCESS}

As the assumptions of parametric tests are likely to be violated for absolute FA (Swaddle et al., 1994), non-parametric statistics were applied to investigate the relation between the number of eggs males had in their nests and all measured metric and meristic variables, including FA.

\section{RESULTS}

\section{FLUCTUATING ASYMMETRY}

Variation in the data due to measurement error was significantly inferior to variation due to $\mathrm{FA}$ for all variables (pectoral fins length: $F_{38,380}=2 \cdot 07$, $P \leq 0.001$; pelvic fins length: $F_{38,380}=10 \cdot 19, \quad P \leq 0.001$; eye spot area: $F_{37,370}=4 \cdot 04, P \leq 0 \cdot 001$; body marks: $\left.F_{37,370}=7 \cdot 32, P \leq 0 \cdot 001\right)$. Frequency distributions of $\mathrm{R}-\mathrm{L}$ did not depart from normality in all variables except in pelvic fins length (Table II). For this variable the kurtosis value was high relative to sample size (Table II), suggesting a leptokurtic distribution, probably caused by outliers with extreme asymmetrical values. After removing the three most extreme asymmetrical individuals, whose values departed from the mean by more than 1.5 S.D., the distribution did not differ from normality $(W=0.97$, $P=0 \cdot 58)$. The mean values of the $\mathrm{R}-\mathrm{L}$ distribution for the four variables did not differ from a mean of zero (Table II). These results suggest that differences between sides for all variables were due to FA.

The values of absolute FA were very high (between 1.53 and $13.30 \%$ of trait size, Table I) when compared to previous studies and all fish exhibited some difference between left and right side measurements for all traits, except in pectoral fins length where one fish had the same value for both sides. Absolute FA relative to trait size $\left[(\mathrm{R}-\mathrm{L})\right.$ trait size $\left.{ }^{-1}\right]$ differed among the four traits (Kruskal-Wallis test, $H=74 \cdot 70, P<0 \cdot 001$ ). The eye spot absolute FA relative to trait size was higher than in any other character (Dunn's test: $Q>3 \cdot 09, P<0 \cdot 01$ for all comparisons, Table I). The number of body marks also presented higher absolute FA values relative to trait size when compared with pectoral and pelvic 
TABLE III. Results from a mixed model, two-way ANOVA to test if absolute FA $[(\mathrm{R}-\mathrm{L})]$ in the different measured traits correlated among individuals

\begin{tabular}{|c|c|c|c|c|}
\hline Source of variation & d.f. & MS & $F$ & $P$ \\
\hline Individuals & 37 & $3 \cdot 744$ & $0 \cdot 98$ & $0 \cdot 51$ \\
\hline Traits & 3 & $185 \cdot 175$ & $48 \cdot 60$ & $<0.001$ \\
\hline Interaction & 111 & $3 \cdot 810^{*}$ & - & - \\
\hline
\end{tabular}

*As no error MS is available (the coefficient of determination is 1) this effect was used as the error term for testing $\mathrm{MS}_{\text {(Individuals) }}$ and $\mathrm{MS}_{\text {(Traits) }}$ (Palmer, 1994).

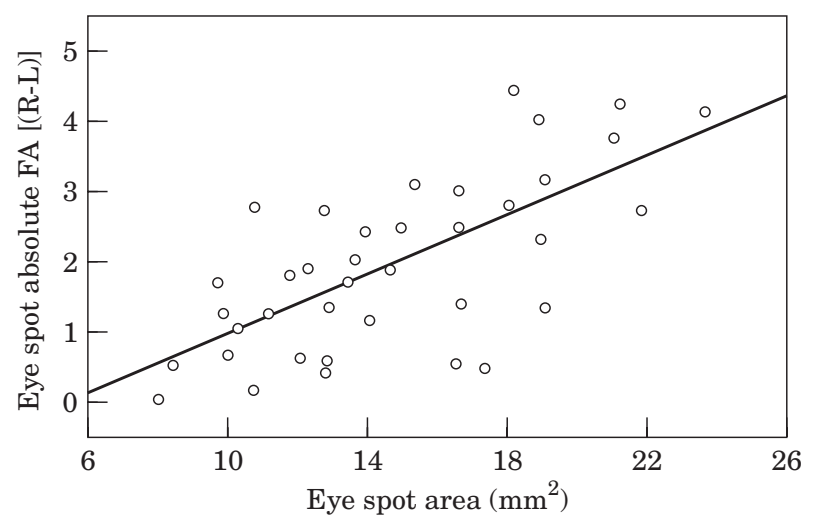

FIG. 1. Relationship between the eye spot absolute FA and the eye spot size.

fins length (Dunn's test: $Q>3 \cdot 72, P<0 \cdot 01$ for both comparisons, Table I). No difference occurred in this measure between pectoral and pelvic fins length (Dunn's test: $Q=0 \cdot 69$, NS, Table I).

Absolute FA in the different measured traits did not correlate among individuals (Table III). The best fit to the relationship between absolute FA of the eyespots and the size of this trait was a linear regression rather than a second order polynomial regression (linear regression: $F_{(1,36)}=32 \cdot 25, P<0 \cdot 0001$; second order polynomial regression: $F_{(2,35)}=15 \cdot 85, P<0 \cdot 0001$, Fig. 1). For the other three characters no relation between trait size and absolute FA was found $(P>0.36$ for both linear and second order polynomial regression). To control for the relation between FA and eye spot size absolute FA was divided by the overall mean size (i.e. the mean of the 12 replicated measures, six for each side) and the product square transformed. The relation between size of the eyespot and this index $\left(I_{\mathrm{FAi}}\right)$ was then marginally non-significant $(P>0.08$ for both linear and second order polynomial regression). For consistency the same scaling procedure was used throughout. The composite index was normally distributed (Shapiro-Wilks' $W=0.98, n=38, P=0.95$ ) and ranged from 30 to 125 .

\section{CORRELATES OF REPRODUCTIVE SUCCESS}

Males that had eggs in their nests were larger than males without eggs (Mann-Whitney test: $Z=-2 \cdot 00, P<0 \cdot 05$ ) and had more developed anal glands, 


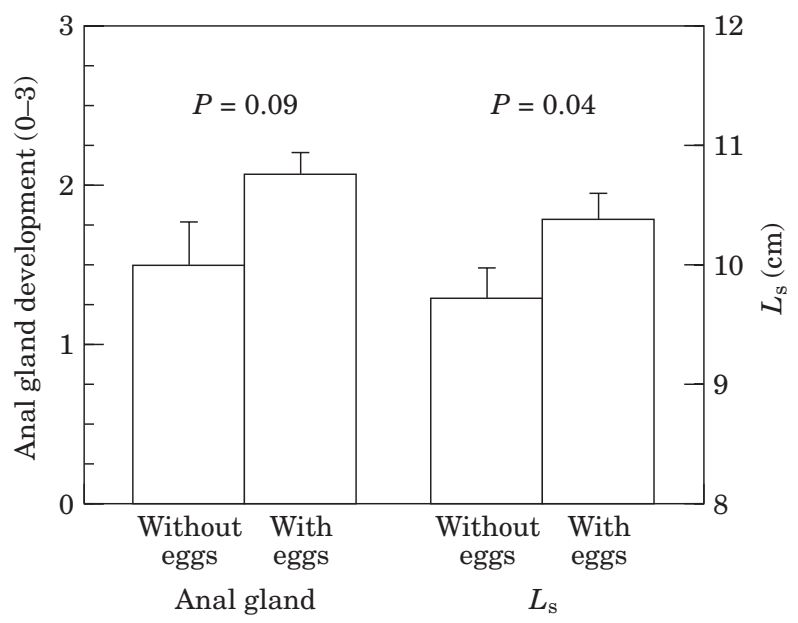

FIG. 2. Differences in the development of the anal gland and standard length between males with $(n=10)$ and without eggs $(n=29)$.

although this difference was not statistically significant $(Z=-1 \cdot 70, P=0 \cdot 09)$ (Fig. 2). $I_{\mathrm{FAi}}$ in each of the four measured traits and $I_{\mathrm{FAc}}$ did not differ between males with and without eggs in their nests $(Z$ varied between -0.77 and -0.03 , $P>0.44$ for all comparisons). Similarly, no difference was found between successful and unsuccessful males in pectoral and pelvic fins length, eye spot area, number of body marks, crest height, dorsal fin height and genital papilla development ( $Z$ varied between -1.32 and $-0.80, P>0.19$ for all variables). The individual significant probability in $L_{\mathrm{s}}$ was, however, superior to the critical Bonferroni probability calculated for the fourteen comparisons performed between males with and without eggs in their nests $\left(P_{0.5}=0.0036\right)$. Considering only the males that had eggs in their nests $(n=29)$ a positive correlation was found between the number of eggs the males were guarding and $L_{\mathrm{s}}$ of the male (Spearman rank correlation: $r_{s}=0.64, n=29, P<0.01$, after the Bonferroni correction). This was not a consequence of bigger males having bigger nests, as no significant correlation was found between the parental male $L_{\mathrm{s}}$ and the nest inner area $\left(r_{s}=0 \cdot 17, n=29, P>0 \cdot 38\right)$. Again, no correlation was found between reproductive success and $I_{\mathrm{FAi}}$ or $I_{\mathrm{FAc}}\left(r_{s}\right.$ varied between $-0 \cdot 16$ and $0 \cdot 13, n=29$, $P>0.42$ for all variables). Similarly, no correlation was found between the number of eggs males were defending and the remaining variables (pectoral and pelvic fins length, eye spot area, number of body marks, crest height, dorsal fin height, anal gland development and genital papilla development; $r_{s}$ varied between -0.24 and $0.30, P>0.11$ for all variables). Breeding males had on average $68 \%$ (S.E. $=5 \cdot 86$, range $=5-98 \%$ ) of the nest inner surface covered with eggs, corresponding to an average of 15380 eggs in their nests (s.E. $=1490$, range $=1232-28$ 976).

\section{DISCUSSION}

It has been suggested that traits with high functional importance are highly canalized during ontogeny, presenting low levels of FA (Palmer \& Strobeck, 
1986; Møller, 1993; Møller \& Pomiankowski, 1993). For example, secondary sexual characters usually present higher FA levels than non-sexual traits (Hunt \& Simmons, 1998). In $S$. pavo, values of absolute FA relative to trait size differed significantly among traits, being higher for the eyespot and body marks than for the pectoral and pelvic fins. This may suggest that the eyespot and the body marks are less canalized during ontogeny. No relationship between either eye spot size or number of body marks with reproductive success, however, was detected. A quantitative comparison of these two traits between sexes could help to clarify if they are being selected by females. The functional value of the pectoral and pelvic fins can also be higher than the eyespot and body marks, being more canalized during development. These fins play an important role in locomotion and thus the efficiency of predator evasions probably depends on their functionality. The pectoral fins are also used to oxygenate the eggs during parental care, and recently Künzler \& Bakker (2000) have demonstrated that the area of the pectoral fins correlates with paternal quality in sticklebacks Gasterosteus aculeatus L.

Absolute FA values relative to trait size were high for all traits (Table I) when compared to previously reported values (usually $<5 \%$ and often $<1 \%$, Palmer, 1994). The population of $S$. pavo that occurs in the Algarve is close to its western limit of distribution. The possible stress caused by sub-optimal environmental conditions may force the fish to allocate energy to cope with extreme physical parameters that would otherwise be available for the development of a stable phenotype (Møller \& Swaddle, 1997). Positive relationships between developmental instability and distance to the distribution centre have been identified in other species (Kiflawi et al., 2000). Adverse environmental conditions have been suggested to intensify directional selection (Endler, 1986) and Møller \& Pomiankowski (1993) have proposed a linear increase in FA with trait size under directional selection. The linear increase in eye spot absolute FA with eye spot size in $S$. pavo may thus arise as a consequence of this being a peripheral population. None of the remaining traits, however, exhibited the same pattern. Measurements of FA in the same traits in other peripheral and central populations of this species may help to clarify this question.

No evidence was found that some of the $S$. pavo males were overall more developmentally stable than others, as no correlation in absolute FA among traits occurred. This is a widespread pattern in studies of FA (Palmer \& Strobeck, 1986) and may be due to small differences in developmental stability among individuals or to the small number of traits assessed (Palmer, 1994).

Previous studies have reported negative correlations between male reproductive success and FA (Møller, 1992) while others did not confirm this prediction (Moodie \& Moodie, 1996; Dufour \& Weatherhead, 1998; Watson \& Thornhill, 1994). No difference in symmetry between successful and unsuccessful males and no correlation between FA and reproductive success among successful males occurred for any of the traits or for the composite index in the present study. These results strongly suggest that FA does not associate significantly with reproductive success among $S$. pavo males.

The relationship between FA and mating success or sexual attractiveness has been the subject of meta-analytical approaches (Møller, 1997; Møller \& Thornhill, 1998; Thornhill \& Møller, 1998) that suggested the existence of an 
overall negative relationship between asymmetry and success in sexual competition (Clarke, 1998). Publication biases, however, can influence the outcome of these studies if significant results are published more often than zero results (Møller \& Thornhill, 1998). Publishing studies that report an absence of relationship between FA and measures of reproductive success is essential to elucidate the real importance of FA in sexual selection. Another crucial problem stated by Clarke (1998) is that many of the studies analysing the relationship between FA and fitness, included in meta-analysis reviews, reported results at the population, rather than at the individual level. It is thus impossible to verify, in these studies, if the relationship holds at the individual level. Future metaanalysis testing the relationship between developmental stability and some measures of fitness would benefit by the inclusion of studies that report results at the individual level.

In $S$. pavo, the only measured variable that correlated with reproductive success was body length. This result is in accordance with previous findings for the same population (Oliveira et al., 1999), according to which successful males of this species are larger than unsuccessful males at this time of the breeding season (June). The same authors also reported that parental males had significantly more developed anal glands in this month than non-parental males. In the present study the development of the anal gland also tended to be larger in males with eggs. The internal nest area did not correlate with $L_{\mathrm{s}}$ among breeding males, suggesting that the reproductive advantage of larger fish may arise as a consequence of female mate choice for larger males and as an advantage when competing for nests. Female mate choice for larger males in fishes has been extensively documented (blennioids, Thompson, 1986; Hastings, 1988a,b; Petersen, 1988; Côté \& Hunt, 1989; general review, Andersson, 1994) and the importance of body size in male-male competition among fishes has also been shown in a number of species (Keenleyside et al., 1985; Sheppey \& Ribbink, 1985; Magnhagen \& Kvarnemo, 1989). Female choice tests for males of different sizes and also for nests of variable quality could determine the mechanism leading to differential reproductive success among breeding males.

The authors would like to thank the Ria Formosa Nature Park for providing essential logistical support. We express our gratitude to I. Schlupp for reviewing the manuscript and to two anonymous referees for their valuable comments. During this study D.M.G. was funded by a PRAXIS XXI Ph.D. grant (BD/13436/97). The study was funded by Fundação para a Ciência e a Tecnologia (UI\&D 331/94; grant PRAXIS/P/BIA/11157/ 98).

\section{References}

Almada, V. C., Gonçalves, E. J., Santos, A. J. \& Baptista, C. (1994). Breeding ecology and nest aggregations in a population of Salaria pavo (Pisces: Blenniidae) in an area where nest sites are very scarce. Journal of Fish Biology 45, 819-830.

Almada, V. C., Gonçalves, E. J., Oliveira, R. F. \& Santos, A. J. (1995). Courting females: ecological constraints affect sex roles in a natural population of the blenniid fish, Salaria pavo. Animal Behaviour 49, 1125-1127.

Andersson, M. (1994). Sexual Selection. Princeton: Princeton University Press.

Clarke, G. M. (1998). Developmental stability and fitness: the evidence is not quite so clear. American Naturalist 152, 762-766. 
Côté, I. M. \& Hunte, W. (1989). Male and female mate choice in the redlip blenny: why bigger is better. Animal Behaviour 38, 78-88.

Dooley, J. K., Tassell, J. V. \& Brito, A. (1985). An annotated checklist of the shorefishes of the Canary Islands. American Museum Novitates 2824, 1-49.

Downhower, J. F., Blumer, L. S., Lejeune, P., Gaudin, P., Marconato, A. \& Bisazza, A. (1990). Otolith asymmetry in Cottus bairdi and Cottus gobio. Polskie Archiwum Hydrobiologii 37, 209-220.

Dufour, K. W. \& Weatherhead, P. J. (1998). Reproductive consequences of bilateral asymmetry for individual male red-winged blackbirds. Behavioral Ecology 9, 232-242.

Endler, J. A. (1986). Natural Selection in the Wild. Princeton: Princeton University Press.

Fishelson, L. (1963). Observations on littoral fishes of Israel. I. Behaviour of Blennius pavo Risso (Teleostei: Blenniidae). Israel Journal of Zoology 12, 67-80.

Hastings, P. A. (1988a). Female choice and male reproductive success in the angel blenny, Coralliozetus angelica (teleostei: Chaenopsidae). Animal Behaviour 36, 115-124.

Hastings, P. A. (1988b). Correlates of male reproductive success in the browncheek blenny, Acanthemblemaria crockeri (Blennioidea: Chaenopsidae). Behavioral Ecology and Sociobiology 22, 95-102.

Hunt, J. \& Simmons, L. W. (1998). Patterns of fluctuating asymmetry in beetle horns: no evidence for reliable signalling. Behavioral Ecology 9, 465-470.

Keenleyside, M. H. A., Rangeley, R. W. \& Kuppers, B. U. (1985). Female mate choice and parental defense behaviour in the cichlid fish Cichlasoma nigrofasciatum. Canadian Journal of Zoology 63, 2489-2493.

Kiflawi, M., Enquist, B. J. \& Jordan, M. A. (2000). Position within the geographic range, relative local abundance and developmental instability. Ecography 23, 539-546.

Künzler, R. \& Bakker, T. C. M. (2000). Pectoral fins and paternal quality in sticklebacks. Proceedings of the Royal Society of London B 267, 999-1004.

Laumen, J., Pern, U. \& Blüm, V. (1974). Investigations on the function and hormonal regulations of the anal appendices in Blennius pavo. Journal of Experimental Zoology 190, 47-56.

Leung, B., Forbes, M. R. \& Houle, D. (2000). Fluctuating asymmetry as a bioindicator of stress: comparing efficacy of analyses involving multiple traits. American Naturalist 155, 101-115.

Magnhagen, C. \& Kvarnemo, L. (1989). Big is better: the importance of size for reproductive success in male Pomatoschistus minutus (Pallas) (Pisces: Gobiidae). Journal of Fish Biology 35, 755-763.

Møller, A. P. (1992). Female swallow preference for symmetrical male sexual ornaments. Nature 357, 238-240.

Møller, A. P. (1993). Developmental stability, sexual selection and speciation. Journal of Evolutionary Biology 6, 493-509.

Møller, A. P. (1994). Sexual selection in the barn swallow (Hirundo rustica). IV. Patterns of fluctuating asymmetry and selection against asymmetry. Evolution 48, 658-670.

Møller, A. P. (1997). Developmental stability and fitness: a review. American Naturalist 149, 916-932.

Møller, A. P. \& Pomiankowski, A. (1993). Fluctuating asymmetry and sexual selection. Genetica 89, 267-279.

Møller, A. P. \& Swaddle, J. P. (1997). Asymmetry, Developmental Stability, and Evolution. Oxford: Oxford University Press.

Møller, A. P. \& Thornhill, R. (1998). Bilateral symmetry and sexual selection: a meta-analysis. American Naturalist 151, 174-192.

Moodie, G. E. E. \& Moodie, E. F. (1996). Do asymmetric sticklebacks make better fathers? Proceedings of the Royal Society of London B 263, 535-539.

Oliveira, R. F., Almada, V. C., Forsgren, E. \& Gonçalves, E. J. (1999). Temporal variation in male traits, nest aggregations and mating success in the peacock 
blenny, Salaria pavo. Journal of Fish Biology 54, 499-512. doi:10.1006/ jfbi.1998.0886.

Palmer, A. R. (1994). Fluctuating asymmetry analyses: a primer. In Developmental Instability: Its Origins and Evolutionary Implications (Markow, T. A., ed.), pp. 335-364. Dordrecht: Kluwer.

Palmer, A. R. \& Strobeck, C. (1986). Fluctuating asymmetry: measurement, analysis and patterns. Annual Review of Ecology and Systematics 17, 391-421.

Pankakoski, E. (1985). Epigenetic asymetry as an ecological indicator in muskrats. Journal of Mammalogy 66, 52-57.

Papaconstantinou, C. A. (1979). Secondary sex characters of blennioid fishes (Pisces: Blenniidae). Thalassographica 1, 57-75.

Patzner, R. A. (1984). The reproduction of Blennius pavo. II. Surface structures of the ripe egg. Zoologisches Anzeiger 21, 44-50.

Patzner, R. A. \& Seiwald, M. (1987). The reproduction of Blennius pavo. II. Secondary sexual organs and accessory glands of the testis during the reproductive cycle. In Proceedings of the Fifth Congress of European Ichthyologists (Kullander, S. \& Fernholm, B., eds), pp. 293-298. Stockholm: Swedish Museum of Natural History.

Patzner, R. A., Seiwald, M., Adlgasser, M. \& Kaurin, G. (1986). The reproduction of Blennius pavo. V. Reproductive behaviour in natural environment. Zoologisches Anzeiger 216, 338-350.

Petersen, C. W. (1988). Male mating success, sexual size dimorphism, and site fidelity in two species of Malacoctenus (Labrisomidae). Environmental Biology of Fishes 3, 173-183.

Sasal, P. \& Pampoulie, C. (2000). Asymmetry, reproductive success and parasitism of Pomatoschistus microps in a French lagoon. Journal of Fish Biology 57, 382-390. doi:10.1006/jfbi.2000.1311.

Schlüter, A., Parzefall, J. \& Schlupp, I. (1998). Female preference for symmetrical vertical bars in male sailfin mollies. Animal Behaviour 56, 147-153.

Sheppey, K. \& Ribbink, A. J. (1985). Mating interruption, an alternative to sexual selection in cichlid fish. South African Journal of Science 81, 702.

Swaddle, J. P., Witter, M. S. \& Cuthill, I. C. (1994). The analysis of fluctuating asymmetry. Animal Behaviour 48, 986-989.

Thompson, S. (1986). Male spawning success and female choice in the mottled triplefin, Forsterygion varium (Pisces: Tripterygiidae). Animal Behaviour 34, 580-589.

Thornhill, R. (1991). Female preference for the pheromone of males with low fluctuating asymmetry in the Japanese scorpionfly (Panorpa japonica: Mecoptera). Behavioral Ecology 3, 277-283.

Thornhill, R. \& Møller, A. P. (1998). The relative importance of size and asymmetry in sexual selection. Behavioral Ecology 9, 546-551.

van Valen, L. (1962). A study of fluctuating asymmetry. Evolution 16, 125-142.

Watson, P. J. \& Thornhill, R. (1994). Fluctuating asymmetry and sexual selection. Trends in Ecology and Evolution 9, 21-25.

Zander, C. D. (1986). Blenniidae. In Fishes of the North-Eastern Atlantic and the Mediterranean (Whithead, P. J., Bauchot, M. L., Hureau, J. C., Nielsen, J. \& Tortenese, E., eds), pp. 1096-1112. Paris: Unesco.

Zeeck, E. \& Ide, V. (1996). The role of sex pheromones in the reproductive behaviour of Blennius pavo (Risso). In Fish Pheromones: Origins and Mode of Action (Canário, A. V. M. \& Power, D., eds), pp. 33-38. Faro: University of Algarve. 